Check for updates

Cite this: RSC Adv., 2019, 9, 12174

Received 20th January 2019

Accepted 7th April 2019

DOI: $10.1039 / c 9 r a 00493 a$

rsc.li/rsc-advances

\section{Effect of ion form of the ion-exchange resin on $\varepsilon-$ poly-L-lysine purification from microbial fermentation broth $\uparrow$}

\begin{abstract}
Xusheng Chen, (D) * Qin Li, Honggang He, Jianhua Zhang and Zhonggui Mao
$\varepsilon$-Poly-L-lysine ( $\varepsilon$-PL) is an added-value natural product with widespread application in the fields of food, pharmaceuticals and biopolymer materials. However, the high production cost reduces its application. To improve the efficiency of $\varepsilon$-PL purification for decreasing the cost of downstream processes, the ion form of the ion-exchange resin, which is widely used for $\varepsilon$-PL purification, was investigated systematically in this study. Among eleven cation-exchange resins tested, the Amberlite IRC-50 resin offered the best adsorption capability and the highest desorption ratio. The adsorption kinetics of IRC-50 resin with $\mathrm{H}^{+}, \mathrm{Na}^{+}$and $\mathrm{NH}_{4}{ }^{+}$ion forms followed a pseudo-second-order model. The dynamic adsorption and desorption parameters of $\varepsilon$ - $\mathrm{PL}$ were optimized with a column packed with IRC-50 resin with $\mathrm{Na}^{+}$and $\mathrm{NH}_{4}{ }^{+}$. It is suggested that $\mathrm{NH}_{4}{ }^{+}$is the optimal ion form of IRC-50 resin for $\varepsilon$-PL extraction. Under optimal conditions, the IRC-50 resin with $\mathrm{NH}_{4}{ }^{+}$achieved the highest $\varepsilon$ - $\mathrm{PL}$ adsorption capability, purity and recovery ratio of $307.96 \mathrm{mg} \mathrm{g}^{-1}, 76.52 \%$ and $96.2 \%$, respectively. After further purification, a final $\varepsilon-P L$ purity of $97.10 \%$ was achieved with a total recovery ratio of $66.01 \%$. This is the first report on improving the $\varepsilon$-PL purification efficiency through optimizing the ion form of the ion-exchange resin. Moreover, it would offer guidance for other natural product recovery processes by ion-exchange chromatography.
\end{abstract}

\section{Introduction}

$\varepsilon$-Poly-L-lysine ( $\varepsilon$-PL), a unique homo-poly(amino acid) with $25-$ $35 \mathrm{~L}$-lysine residuals linked by $\varepsilon$-amino and $\alpha$-carboxyl groups, is produced by various Streptomycetaceae and some Bacillus bacteria and a few filamentous fungi as a secondary metabolite. ${ }^{1,2} \varepsilon$-PL has a strong antimicrobial activity towards Grampositive and Gram-negative bacteria, yeast, fungi and viruses. ${ }^{3}$ Moreover, $\varepsilon$-PL is water soluble, biodegradable and has high food safety. ${ }^{4}$ Thus, it is approved as a natural food preservative by the US Food and Drug Administration as GRAS (Generally Regarded as Safe) since 2004. To date, $\varepsilon$-PL has been used in the food industry in Japan and South Korea for nearly 30 years, and has maintained rapid growth in the United States, Europe and China in recent years. Moreover, $\varepsilon$-PL also has wide potential application in the fields of pharmaceuticals and biopolymer materials. ${ }^{5}$ Hence, $\varepsilon$-PL is a value-added natural product with widespread application in industry.

Although $\varepsilon$-PL has been manufactured on an industrial scale, its high cost restricts its widespread application in industry,

The Key Laboratory of Industrial Biotechnology, Ministry of Education, School of Biotechnology, Jiangnan University, 1800 Lihu Road, Wuxi 214122, Jiangsu, China. E-mail: chenxs@jiangnan.edu.cn; Fax: +86 510 85918296; Tel: +86 51085918296

$\uparrow$ Electronic supplementary information (ESI) available: Fig. S1-S3 and Tables S1-S8. See DOI: 10.1039/c9ra00493a especially in the food industry. In recent decades, extensive efforts have been devoted to improving $\varepsilon$-PL-producing strains and to optimize bioprocesses, ${ }^{6}$ to achieve $\varepsilon$-PL production that exceeds $20 \mathrm{~g} \mathrm{~L}^{-1}$, and the highest $\varepsilon$-PL production has reached $54.7 \mathrm{~g} \mathrm{~L}^{-1}$. Downstream processing costs can reach $50-70 \%$ of the total production cost in industrial biotechnology fields. ${ }^{8}$ However, few studies have investigated $\varepsilon$-PL bioseparation from fermentation broth. The first report on $\varepsilon$-PL purification used cation ion-exchange adsorption, activated-carbon decoloration, organic-solvent precipitation, and gel chromatography to identify the $\varepsilon$-PL chemical structure. ${ }^{9}$ Using this approach, Bankar et al. ${ }^{10}$ purified $\varepsilon$-PL from fermentation broth that contained $2 \mathrm{~g} \mathrm{~L}^{-1} \varepsilon$-PL with a purity of $97.58 \%$ and a recovery ratio of $90.42 \%$. Zhu et al. ${ }^{11}$ evaluated the $\varepsilon$-PL adsorption performances of HZB-3B (strong cation) and D155 (weak cation) resins and optimized the adsorption and desorption conditions, and achieved the highest desorption efficiency by $97.57 \%$ and the overall recovery by $94.49 \%$. In addition, an ultrafiltration technique with 2 and $5 \mathrm{kDa}$ cut-off molecular weights has been used to prepare $\varepsilon$-PL with different molecular weights from a crude extract of $\varepsilon$-PL hydrochloride. ${ }^{12}$ Recently, Katano et al. ${ }^{13}$ proposed a precipitation method to separate and purify $\varepsilon$-PL from $100 \mu \mathrm{L}$ culture broth with tetraphenylborate anion. A metal-chelate affinity precipitation was used for $\varepsilon$-PL purification and achieved electrophoretic purity with a recovery ratio of $98.42 \% .{ }^{14}$ Although both novel methods could extract $\varepsilon$-PL from 
the fermentation broth, investigations are required before applying them in industry because of food-safety or cost-related concerns.

In previous studies, we developed a potential industrial scheme for $\varepsilon$-PL separation and purification from fermentation broth, including mycelia removal by flocculation, macromolecule removal by $30 \mathrm{kDa}$ ultrafiltration, ion-exchange adsorption, decolorization with a macroporous resin and small-molecule removal by $1 \mathrm{kDa}$ ultrafiltration. A $90.2 \%$ purity and $75 \%$ recovery have been achieved..$^{15}$ However, the purity of the resultant $\varepsilon$-PL does not meet standard requirements (purity > $95 \%)$. Based on an analysis of $\varepsilon$-PL bioseparation, ion exchange has been proven a key step for enhancing the $\varepsilon$-PL purity in this scheme, but the type of resin and exchange ion form have not been investigated. To improve the $\varepsilon$-PL purity and its efficiency, eleven cation-exchange resins were compared in terms of adsorption capacities and desorption ratio. Also, the adsorption kinetics of Amberlite IRC-50 with different ionic forms was characterized. Parameters of $\varepsilon$-PL adsorption and desorption on Amberlite IRC-50 with $\mathrm{Na}^{+}$and $\mathrm{NH}_{4}{ }^{+}$under static and dynamic conditions were optimized. Finally, $\varepsilon$-PL with standard requirements was prepared using Amberlite IRC-50 with $\mathrm{NH}_{4}{ }^{+}$ under optimal conditions with the help of activated carbon and ultrafiltration.

\section{Materials and methods}

\subsection{Preparation and pre-treatment of $\varepsilon$-PL fermentation broth}

The fermentation broth contained $\varepsilon$-PL with the concentration of around $40 \mathrm{~g} \mathrm{~L}^{-1}$ was prepared in a $5 \mathrm{~L}$ fermenter with glucose as carbon source by Streptomyces albulus M-Z18 using pH shock strategy. ${ }^{7}$ Fresh fermentation broth was centrifuged at $4500 \times g$ for $20 \mathrm{~min}$ in several batches to remove mycelia, and then pooled supernatant and subjected to an ultrafiltration system (Pellicon 2 mini, Merck Millipore, MA, USA) coupled with a membrane package $\left(0.1 \mathrm{~m}^{2}\right)$ with the cut-off molecular weight of $30 \mathrm{kDa}$ under $0.10-0.15 \mathrm{MPa}$ inlet pressure as described in our previous study. ${ }^{15}$ The filtrate was collected with the $\varepsilon$-PL concentration of $8 \mathrm{~g} \mathrm{~L}^{-1}$ and used in this study.

\subsection{Adsorbents and pre-treatment}

Eleven ion exchange resins, including two strong acidic cation exchange resins (HD-8 and HZD-3B) and nine weak acidic cation exchange resins (D113, HZD-2, DK110, D115, HD-2, D152, D155C, D151, Amberlite ${ }^{\circledR}$ IRC-50) were provided by Shanghai Huazhen Technology Co., Ltd. (Shanghai, China), Chemical Plant of Nankai University (Tianjin, China) and Sigma-Aldrich Chemical Company, Inc. (Milwaukee, WI, USA) in $\mathrm{H}^{+}$form. Their physical properties and specification are shown in Table S1. $\dagger$ The fresh resins were washed firstly with deionized water to remove impurities, and then 5 times resin volume of $1.0 \mathrm{~mol} \mathrm{~L}^{-1} \mathrm{HCl}, 1.0 \mathrm{~mol} \mathrm{~L}^{-1} \mathrm{NaOH}$ and $1.0 \mathrm{~mol} \mathrm{~L}^{-1}$ $\mathrm{HCl}$ were sequentially used to treat these resins at $150 \mathrm{rpm}$ shaking for $4 \mathrm{~h}$ at $25{ }^{\circ} \mathrm{C}$, respectively. In particular, the Amberlite IRC-50 with $\mathrm{Na}^{+}$was converted from $\mathrm{H}^{+}$form followed by 5 times resin volume of $1.0 \mathrm{~mol} \mathrm{~L}^{-1} \mathrm{NaOH}$, $1.0 \mathrm{~mol} \mathrm{~L}^{-1} \mathrm{HCl}$, and $1.0 \mathrm{~mol} \mathrm{~L}^{-1} \mathrm{NaOH}$ treating. Similarly, the Amberlite IRC-50 with $\mathrm{NH}_{4}{ }^{+}$was prepared by 5 times resin volume of $1.0 \mathrm{~mol} \mathrm{~L}^{-1} \mathrm{NH}_{3} \cdot \mathrm{H}_{2} \mathrm{O}, 1.0 \mathrm{~mol} \mathrm{~L}^{-1} \mathrm{HCl}$, and $1.0 \mathrm{~mol} \mathrm{~L}^{-1} \mathrm{NH}_{3} \cdot \mathrm{H}_{2} \mathrm{O}$ at the same condition as other resins. In the process of resins activation or conversion, each operation of $\mathrm{HCl}, \mathrm{NaOH}$ or $\mathrm{NH}_{3} \cdot \mathrm{H}_{2} \mathrm{O}$ treatment was finished, deionized water was used to remove the residual $\mathrm{HCl}, \mathrm{NaOH}$ or $\mathrm{NH}_{3} \cdot \mathrm{H}_{2} \mathrm{O}$ until the $\mathrm{pH}$ was reached around neutral. Finally, these pretreated resins were collected by vacuum filtration and stored in glass-stoppered bottles at room temperature for follow study.

\subsection{Static adsorption and desorption experiments}

To test adsorption and desorption properties of 11 resins, each pre-treated resin with the weight of $5.0 \mathrm{~g}$ was added into $500 \mathrm{~mL}$ flask containing $100 \mathrm{~mL}$ pre-treated fermentation broth with the $\mathrm{pH}$ of 7.5. Then, the flask was placed onto a shaker with $150 \mathrm{rpm}$ for $6.0 \mathrm{~h}$ at $25{ }^{\circ} \mathrm{C}$. After that, the resin was collected by filtration and rinsed by $100 \mathrm{~mL}$ deionized water to remove the residual sample solution. Subsequently, the resin was desorbed by $200 \mathrm{~mL} 0.1 \mathrm{~mol} \mathrm{~L}^{-1} \mathrm{HCl}$ in $500 \mathrm{~mL}$ flask with $150 \mathrm{rpm}$ shaking for $12 \mathrm{~h}$ at $25^{\circ} \mathrm{C}$. The $\varepsilon$-PL concentrations before and after adsorption were detected, and the capacity of adsorption $\left(Q_{\mathrm{e}}\right.$, eqn (1)) and the desorption ratio $(D$, eqn (2)) were quantified as the following equations:

$$
\begin{gathered}
Q_{\mathrm{e}}=\frac{\left(C_{0}-C_{\mathrm{e}}\right) V_{\mathrm{i}}}{W} \\
D=\frac{C_{\mathrm{d}} V_{\mathrm{d}}}{C_{0}-C_{\mathrm{e}}} \times 100 \%
\end{gathered}
$$

where, $Q_{\mathrm{e}}\left(\mathrm{mg} \mathrm{g}^{-1}\right)$ is the adsorption capacity, $C_{0}$ and $C_{\mathrm{e}}(\mathrm{mg}$ $\mathrm{mL}^{-1}$ ) are the initial and equilibrium concentrations of $\varepsilon$-PL in the solution, respectively. $V_{\mathrm{i}}(\mathrm{mL})$ is the volume of initial sample solution, $W(\mathrm{~g})$ is the weight of the tested resin. $D(\%)$ is the desorption ratio, $C_{\mathrm{d}}$ is the $\varepsilon$-PL concentrations of desorption solution, $V_{\mathrm{d}}(\mathrm{mL})$ is the eluent volume.

For evaluation the effect of sample $\mathrm{pH}$ on $\varepsilon$-PL adsorption capacity of IRC-50 resin with $\mathrm{H}^{+}, \mathrm{Na}^{+}$and $\mathrm{NH}_{4}{ }^{+}, 1.0 \mathrm{~g}$ pretreated IRC-50 resin with $\mathrm{H}^{+}, \mathrm{Na}^{+}$and $\mathrm{NH}_{4}{ }^{+}$forms were added into $250 \mathrm{~mL}$ flasks containing $50 \mathrm{~mL}$ sample solution with the pHs of 3.0, 4.0, 5.0, 6.0, 7.0, 8.0, 9.0, 10.0, respectively. These flasks were placed onto a shaker with $150 \mathrm{rpm}$ for $6 \mathrm{~h}$ at $25{ }^{\circ} \mathrm{C}$. After that, the $\varepsilon$-PL concentration before and after adsorption was detected, and the capacity of adsorption was quantified by eqn (1). At the same time, resins were collected by vacuum filtration and rinsed by deionized water to remove the residual sample solution. Subsequently, IRC-50 resins with $\mathrm{H}^{+}, \mathrm{Na}^{+}$and $\mathrm{NH}_{4}{ }^{+}$ were desorbed by $50 \mathrm{~mL} \mathrm{HCl}, \mathrm{NaOH}$ and $\mathrm{NH}_{3} \cdot \mathrm{H}_{2} \mathrm{O}$ with the concentrations of $0.02,0.05,0.1,0.2,0.4$ and $0.6 \mathrm{~mol} \mathrm{~L}^{-1}$ in $250 \mathrm{~mL}$ flasks with $150 \mathrm{rpm}$ shaking for $6 \mathrm{~h}$ at $25{ }^{\circ} \mathrm{C}$, respectively. The concentration of $\varepsilon$-PL in eluent was detected, and the ratio of desorption was quantified as eqn (2).

To obtain the static adsorption kinetics of $\varepsilon$-PL on the Amberlite IRC-50 with $\mathrm{H}^{+}, \mathrm{Na}^{+}$and $\mathrm{NH}_{4}{ }^{+}, 1.0 \mathrm{~g}$ pre-treated Amberlite IRC-50 resins were added into $250 \mathrm{~mL}$ flasks containing $50 \mathrm{~mL}$ standard $\varepsilon$-PL solution $\left(10.0 \mathrm{~g} \mathrm{~L}^{-1}\right)$ with the $\mathrm{pH}$ of 
8.0, respectively. These flasks were placed onto a shaker with $150 \mathrm{rpm}$ at $25^{\circ} \mathrm{C}$ for $3 \mathrm{~h}$, and $1.0 \mathrm{~mL}$ solution was withdrawn from each flask in every $10 \mathrm{~min}$ in the first $1.0 \mathrm{~h}, 20 \mathrm{~min}$ in the second $1.0 \mathrm{~h}$, and $30 \mathrm{~min}$ in the last $1.0 \mathrm{~h}$. The sample was subjected to detect the concentration of $\varepsilon$-PL, and calculated the corresponding adsorption capacity of every ion form in each time point as eqn (1). Then, these data were used to plot the static adsorption kinetic curves. In this study, the pseudo firstorder equation and pseudo second-order equation were employed to describe the mechanism of $\varepsilon$-PL on Amberlite IRC50 with different ion forms. The pseudo first-order equation, also known as Lagergren's equation, is the earliest known equation describing the adsorption rate based on adsorption capacity (3). It can be represented in a linear form as:

$$
\ln \left(Q_{\mathrm{e}}-Q_{t}\right)=\ln Q_{\mathrm{e}}-\frac{K_{1} t}{2.303}
$$

where $Q_{\mathrm{e}}$ and $Q_{t}$ are the amounts of $\varepsilon$-PL adsorbed at equilibrium and time $t\left(\mathrm{mg} \mathrm{g}^{-1}\right)$, respectively; $K_{1}$ is the rate constant of pseudo first-order equation $(1 / \mathrm{min})$.

Therefore, the first-order rate constant $K_{1}$ and equilibrium adsorption capacity $Q_{\mathrm{e}}$ can be calculated from the slope $\left(K_{1}\right)$ 2.303) and the intercept $\left(\ln Q_{\mathrm{e}}\right)$ by plotting $\ln \left(Q_{\mathrm{e}}-Q_{t}\right)$ versus $t$.

The pseudo second-order equation can be used to model the two-site-occupancy adsorption kinetics, i.e., the adsorbate molecule reacts with two adsorption sites (4). The equation is commonly used in its linearized form as:

$$
\frac{t}{Q_{t}}=\frac{1}{K_{2} Q_{\mathrm{e}}{ }^{2}}+\frac{t}{Q_{\mathrm{e}}}
$$

where $K_{2}$ is the rate constant $\left(\mathrm{g} \mathrm{mg}^{-1} \mathrm{~min}^{-1}\right)$.

Therefore, the values for $K_{2}$ and $Q_{\mathrm{e}}$ can be estimated from the slope and the intercept, respectively, in the plot of $t / Q_{t}$ versus $t$.

\subsection{Dynamic adsorption and desorption experiments}

In this study, dynamic adsorption and desorption tests were performed in a chromatographic system contained six glass columns $(20 \times 200 \mathrm{~mm})$ and a multichannel peristaltic pump (BT100-1F, Longer Precision Pump Co. Ltd, Baoding, China). Each column was packed IRC-50 resins with $\mathrm{Na}^{+}$or $\mathrm{NH}_{4}^{+}$at the bed volume (BV) of $31.4 \mathrm{~mL}$.

To investigate the effect of sample $\mathrm{pH}$ on $\varepsilon$-PL adsorption at dynamic experiment, the sample $\mathrm{pH}$ was varied from 5.5 to 8.5, and the pre-treated fermentation broth were loaded onto columns contained IRC-50 with $\mathrm{Na}^{+}$or $\mathrm{NH}_{4}{ }^{+}$at a flow rate of 5.0 $\mathrm{BV} \mathrm{h}^{-1}$. During loading, the presence of $\varepsilon$-PL in the effluent was monitored by Dragendorff reagent at every $10.0 \mathrm{~mL}$ interval. Once a noticeable Dragendorff positive precipitate producing, it means the adsorption was nearly reached equilibrium. The concentration of $\varepsilon$-PL in effluent was determined and used for calculating adsorption capacity. In addition, the leakage point in this study was defined as the concentration of $\varepsilon$-PL in the effluent solutions reached $5 \%$ of the initial concentration.

To investigate the effect of flow rate on $\varepsilon$-PL adsorption at dynamic experiment, the flow rate was varied from 2.0 to $7.0 \mathrm{BV}$ $\mathrm{h}^{-1}$. The sample solution was divided into two parts, and their pHs were adjusted to $\mathrm{pH} 7.0$ and $\mathrm{pH} 7.5$ for loading onto columns contained IRC-50 resins with $\mathrm{Na}^{+}$and $\mathrm{NH}_{4}^{+}$, respectively. Other operation conditions are the same as the above mentioned $\mathrm{pH}$ optimization.

In addition, the dynamic breakthrough curves of IRC-50 resins with $\mathrm{Na}^{+}$and $\mathrm{NH}_{4}^{+}$were prepared at their optimal conditions: the sample $\mathrm{pH}$ of 7.0 for IRC-50 resin with $\mathrm{Na}^{+}$, and $\mathrm{pH} 7.5$ for IRC-50 resin with $\mathrm{NH}_{4}{ }^{+}$; the flow rates all at 5.0 BV $\mathrm{h}^{-1}$. The effluent was collected in every BV, and the contents of $\varepsilon$-PL, protein, pigment as well as $\mathrm{pH}$ value were detected, and used for generating the dynamic breakthrough curves. To monitor the presence of $\varepsilon$-PL in the effluent in time, Dragendorff reagent was also adopted.

After the adsorption equilibrium of IRC-50 resins with $\mathrm{Na}^{+}$ and $\mathrm{NH}_{4}{ }^{+}$at the optimal uploading conditions, the resin column was washed by $4.0 \mathrm{BV}$ deionized water at the flow rate of $2.0 \mathrm{BV}$ $\mathrm{h}^{-1}$. To investigate the effect of eluent concentration and flow rate on dynamic desorption, the eluents $\left(\mathrm{NaOH}\right.$ or $\left.\mathrm{NH}_{3} \cdot \mathrm{H}_{2} \mathrm{O}\right)$ concentrations varied from 0.05 to $0.3 \mathrm{~mol} \mathrm{~L}^{-1}$, and flow rates varied from 1.0 to $3.0 \mathrm{BV} \mathrm{h}^{-1}$. Moreover, the dynamic elution curves of IRC-50 resins with $\mathrm{Na}^{+}$and $\mathrm{NH}_{4}{ }^{+}$were prepared at the optimal conditions: IRC-50 resin with $\mathrm{Na}^{+}$was eluted by $0.15 \mathrm{~mol} \mathrm{~L}^{-1} \mathrm{NaOH}$, IRC-50 resin with $\mathrm{NH}_{4}^{+}$was eluted by $0.2 \mathrm{~mol} \mathrm{~L}^{-1} \mathrm{NH}_{3} \cdot \mathrm{H}_{2} \mathrm{O}$ and the flow rates were all $2.0 \mathrm{BV} \mathrm{h}^{-1}$.

\subsection{Further purification of $\varepsilon$-PL by activated carbon and ultrafiltration}

To further improve the purity of $\varepsilon$-PL prepared by IRC-50 resins with $\mathrm{NH}_{4}{ }^{+}$, the elution was adjusted to $\mathrm{pH} 4.0$ using $1 \mathrm{~mol} \mathrm{~L}^{-1}$ $\mathrm{HCl}$ at first, and then subjected to decolour by active carbon $(1 \%, \mathrm{w} / \mathrm{v})$ at $80{ }^{\circ} \mathrm{C}$ for $20 \mathrm{~min}$. Subsequently, the activated carbon was removed by vacuum filtration and the filtrate was desalted by ultrafiltration with the cut-off molecular weight of $1.0 \mathrm{kDa}$ membrane $\left(0.1 \mathrm{~m}^{2}\right)$ using ultrafiltration system (Pellicon 2 mini, Merck Millipore, MA, USA). The specific operation parameters have been described in our previous study. ${ }^{\mathbf{1 6}}$

\subsection{Analytical methods}

The $\varepsilon$-PL concentration was determined using methyl orange method. ${ }^{17}$ In brief, an equal volume of sample with 0.06-0.12 g $\mathrm{L}^{-1} \varepsilon$-PL diluted with $0.07 \mathrm{mM}$ phosphate buffer ( $\mathrm{pH}$ 6.90) and $0.7 \mathrm{mM}$ methyl orange solution were mixed together, which reacted at $30{ }^{\circ} \mathrm{C}$ with shaking for $30 \mathrm{~min}$. The interaction of cationic $\varepsilon$-PL with anionic methyl orange in the mixture led to form a water-insoluble complex, the $\varepsilon$-PL concentration can be estimated from the absorbance at $465 \mathrm{~nm}$ of the methyl orange remaining in the supernatant solution through standard curve calculation. The recovery ratio of $\varepsilon-\mathrm{PL}$ is calculated as following:

$$
\varepsilon \text {-PL recovery ratio }(\%)=\frac{C_{1} \times V_{1}}{C_{0} \times V_{0}} \times 100 \%
$$

where, $C_{0}$ and $C_{1}\left(\mathrm{mg} \mathrm{mL}^{-1}\right)$ are the concentrations of $\varepsilon$-PL in initial sample and elution, respectively. $V_{0}$ and $V_{1}(\mathrm{~mL})$ are the volumes of $\varepsilon$-PL in initial sample and elution, respectively.

The protein concentration was determined using the Bradford protein assay kit with bovine serum albumin as the standard. ${ }^{18}$ The removal ratio of protein is calculated as following: 
Protein removal ratio $(\%)=\frac{P_{0} \times V_{0}-P_{1} \times V_{1}}{P_{0} \times V_{0}} \times 100 \%$

where, $P_{0}$ and $P_{1}\left(\mathrm{mg} \mathrm{mL}^{-1}\right)$ are the concentrations of protein in the sample before and after adsorption by resin, respectively. $V_{0}$ and $V_{1}(\mathrm{~mL})$ are the volumes of the sample before and after adsorption by resins, respectively.

The pigment concentration is expressed as the absorbance of the sample at $410 \mathrm{~nm}$ on a spectrophotometer. To make sure the absorbance in the range of $0.2-0.6$, deionized water was used to dilute the samples. The removal ratio of pigment is calculated as following:

$$
\text { Pigment removal ratio(\%) }=\frac{R_{0} \times V_{0}-R_{1} \times V_{1}}{R_{0} \times V} \times 100 \%
$$

where, $R_{0}$ and $R_{1}$ are the absorbance values of the sample before and after adsorption by resin, respectively. $V_{0}$ and $V_{1}(\mathrm{~mL})$ are the volumes of the sample before and after adsorption of resins, respectively.

The purified $\varepsilon$-PL and its extraction process were also analyzed by HPLC (Chromaster, Hitachi, Japan) equipped with an ODS-120T column $(4.6 \mathrm{~mm} \times 250 \mathrm{~mm}$; Tosho Co., Ltd., Tokyo) and a UV spectrophotometer detector (Chromaster, Hitachi, Japan). The mobile phase was $10 \mathrm{mM} \mathrm{K}_{2} \mathrm{HPO}_{4}$ and $10 \mathrm{mM} \mathrm{Na}_{2} \mathrm{SO}_{4}$ aqueous solution ( $\mathrm{pH} 3.4$ adjusted by $\mathrm{H}_{3} \mathrm{PO}_{4}$ ): acetonitrile $(23: 2, \mathrm{v} / \mathrm{v})$ at a flow rate of $0.4 \mathrm{~mL} \mathrm{~min}^{-1}$. The operating conditions were as follows: monitoring wavelength, $215 \mathrm{~nm}$; injection volume, $100 \mu \mathrm{L}$; column temperature, $30^{\circ} \mathrm{C}$. The purity of the purified $\varepsilon$-PL is calculated as following:

$$
\varepsilon \text {-PL purity }(\%)=\frac{C \times V}{m} \times 100 \%
$$

where, $C$ is the $\varepsilon$-PL concentration determined by HPLC, $V$ is the volume of the sample, $m$ is the weight of the purified $\varepsilon$-PL sample.

The distribution of $\varepsilon$-PL chain length was characterized by MALDI-TOF-MS (Autoflex 2, Bruker Daltonics Inc., USA) and 2,5dihydroxybenzoic acid was used as a matrix. ${ }^{19}$

\subsection{Statistical analysis}

All values were detected in triplicate, and expressed as means \pm $\mathrm{SD}$. The differences of the experimental results were analysed by Student's $t$-test with $p<0.05$ as significant.

\section{Results and discussion}

\subsection{Adsorption and desorption capacities of $\varepsilon$-PL on cation-} exchange resins

The chemical structure of $\varepsilon$-PL shows an equal number of amino groups to its polymerization degree, and its isoelectric point (pI) occurs at around $\mathrm{pH}$ 9.0. ${ }^{20}$ Thus, the $\varepsilon$-PL would exhibit features of a multi-cation when the solution $\mathrm{pH}$ is lower than 9.0, and a cation-exchange resin is used for $\varepsilon$-PL extraction from the fermentation broth as an adsorbent. As shown in Fig. 1, two strong acidic resins (HD-8 and HZD-3B) and nine weak acidic resins (D113, HZD-2, DK110, D115, HD-2, D152, D155C, D151, Amberlite IRC-50) were evaluated in terms of

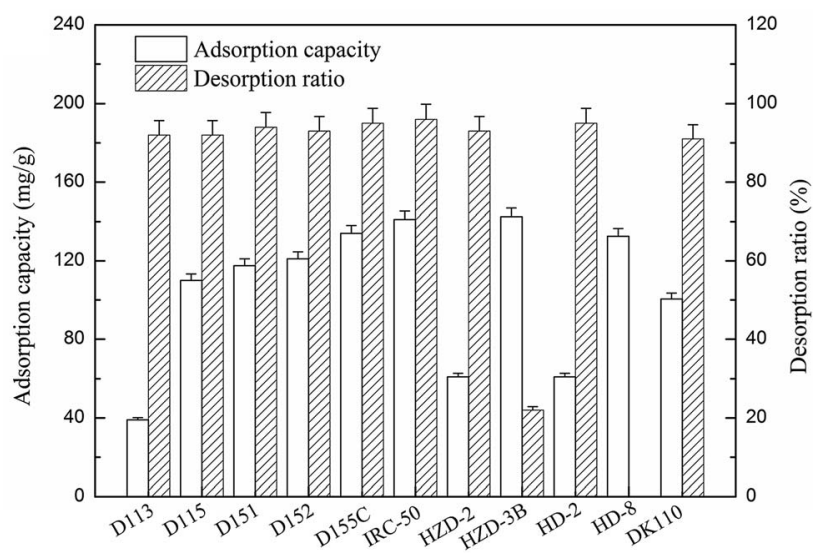

Fig. 1 The static adsorption capacity and desorption ratio of $\varepsilon-P L$ on different cation exchange resins.

their $\varepsilon$-PL adsorption capacity and desorption ratio. The adsorption capacities of IRC-50 and HZD-3B resins exceeded $140 \mathrm{mg} \mathrm{g}^{-1}$, which suggests that both resins had a better adsorption selectivity for $\varepsilon$-PL compared with the others. Moreover, the IRC-50 resin showed the highest desorption ratio among the resins for $\varepsilon$-PL at $96.0 \%$, which means that it has a better desorption capacity. However, the HZD-3B resin exhibited the lowest desorption ratio of only $22.0 \%$ among resins, except HD-8, which was approximately $70 \%$ lower than that of the IRC-50 resin, and which indicates that $\varepsilon$-PL dissociated with difficulty from HZD-3B. It might be $\mathrm{HCl}$ is not the best eluent for strong cation resin HZD-3B desorption. Considering economical in industrial application, the weak acidic resin IRC-50 was selected for $\varepsilon$-PL extraction from fermentation broth as an adsorbent in this study.

\subsection{Static adsorption and desorption of $\varepsilon$-PL on Amberlite IRC-50 with different ion forms}

An ion-exchange resin with different ion forms may result in a different adsorption capacity. The sample $\mathrm{pH}$ would determine the type and quantity of ionization of solute and resin. Thus, the $\varepsilon$-PL adsorption capacities of IRC-50 with $\mathrm{H}^{+}, \mathrm{Na}^{+}$and $\mathrm{NH}_{4}{ }^{+}$at different $\mathrm{pHs}$ were investigated, and the results are shown in Fig. 2a. The effect of $\mathrm{pH}$ on $\varepsilon$-PL adsorption on the resin with three ion forms was consistent. From pH 3.0 to 8.0, the $\varepsilon$-PL adsorption capacities of the three resins increased with
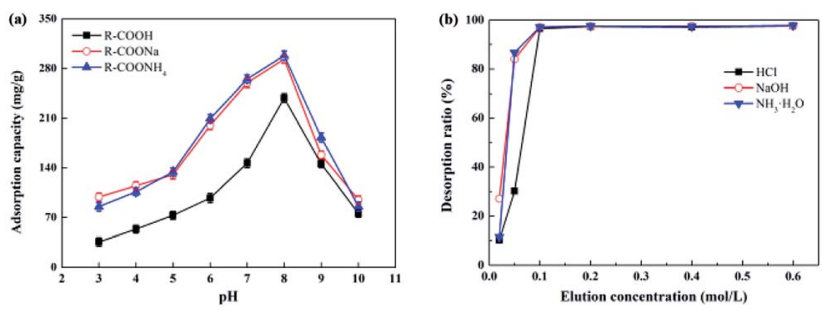

Fig. 2 Effect of $\mathrm{pH}$ (a) and eluent concentration (b) on the static adsorption capacity and desorption ratio of $\varepsilon$ - $\mathrm{PL}$ on Amberlite IRC-50 resin with $\mathrm{H}^{+}, \mathrm{Na}^{+}$and $\mathrm{NH}_{4}{ }^{+}$ion forms, respectively. 
an increase in $\mathrm{pH}$, and the maximum adsorption capacities reached 238.7, 293.3 and $298.1 \mathrm{mg} \mathrm{g}^{-1}$ at $\mathrm{pH} 8.0$, respectively. However, when the $\mathrm{pH}$ was increased to 10.0 , the $\varepsilon$-PL adsorption capacities decreased sharply. As a result, the optimal $\mathrm{pH}$ for $\varepsilon$-PL adsorption using the IRC-50 resin with $\mathrm{H}^{+}, \mathrm{Na}^{+}$and $\mathrm{NH}_{4}{ }^{+}$ ion forms were the same at 8.0, which is consistent with a previous study. ${ }^{9}$ However, the $\varepsilon$-PL adsorption capacity of the IRC-50 resin with $\mathrm{H}^{+}$was lower than that of the $\mathrm{Na}^{+}$and $\mathrm{NH}_{4}{ }^{+}$ ion forms of $22.9 \%$ and $24.9 \%$, respectively. This might be derived from the IRC-50 resin with $\mathrm{H}^{+}$result in the sample $\mathrm{pH}$ lower than that with $\mathrm{Na}^{+}$and $\mathrm{NH}_{4}{ }^{+}$ion forms (Fig. S1 $\dagger$ ).

Carboxyl is the functional group of the IRC-50 resin, and its dissociation constant $\left(\mathrm{p} K_{\mathrm{a}}\right)$ is $\sim 3.9 .^{21}$ Therefore, when the solution $\mathrm{pH}$ ranged from 3.0 to 8.0, the dissociation of carboxyl was stronger with an increase in $\mathrm{pH}$, and resulted in a rapid increase in $\varepsilon$-PL adsorption capacity. Although the dissociation of carboxyl would be improved with an increase in $\mathrm{pH}$ from 8.0 to 10.0 , the $\varepsilon$-PL charge would change from positive to negative because its $\mathrm{pI}$ is $9.0{ }^{20}$ Therefore, $\mathrm{pH} 8.0$ was determined as the optimum $\mathrm{pH}$ for $\varepsilon$-PL extraction using IRC-50 resin with $\mathrm{H}^{+}, \mathrm{Na}^{+}$ and $\mathrm{NH}_{4}{ }^{+}$ion forms.

To facilitate resin regeneration, $\mathrm{HCl}, \mathrm{NaOH}$ and ammonia were used as eluents for the IRC-50 resin with $\mathrm{H}^{+}, \mathrm{Na}^{+}$and $\mathrm{NH}_{4}{ }^{+}$. As shown in Fig. $2 \mathrm{~b}$, the $\varepsilon$-PL desorption ratios of three resins increased rapidly when the corresponding eluent concentrations increased from 0.02 to $0.1 \mathrm{~mol} \mathrm{~L}^{-1}$. Interestingly, these resins achieved their maximum $\varepsilon$-PL desorption ratios of $96 \%$ at an eluent concentration of $0.1 \mathrm{~mol} \mathrm{~L}^{-1}$. However, the $\varepsilon-\mathrm{PL}$ desorption ratios could not be improved further with an increase in eluent concentration.

Although $\mathrm{HCl}, \mathrm{NaOH}$ and ammonia at $0.1 \mathrm{~mol} \mathrm{~L}^{-1}$ concentrations had the same desorption effects towards $\varepsilon$-PL on the IRC-50 resin with $\mathrm{H}^{+}, \mathrm{Na}^{+}$and $\mathrm{NH}_{4}{ }^{+}$ion forms, their desorption mechanisms differed. $\mathrm{HCl}$ relies on the ion-exchange principle to replace the adsorbed $\varepsilon$-PL from resin because the weak acidic resin IRC-50 can combine $\mathrm{H}^{+}$as a priority. $\mathrm{NaOH}$ and ammonia depend on a change in charge properties of the $\varepsilon$-PL from positive to negative, and finally dissociate from the resin. The higher eluent concentration could reduce the eluent volume used, but it would introduce additional salt in the following neutralization reaction, which would increase the desalination burden during operation. Therefore, $0.1 \mathrm{~mol} \mathrm{~L}^{-1} \mathrm{HCl}, \mathrm{NaOH}$ and ammonia were used for the IRC-50 resins with $\mathrm{H}^{+}, \mathrm{Na}^{+}$and $\mathrm{NH}_{4}{ }^{+}$as eluents, respectively.

\subsection{Static adsorption kinetics of $\varepsilon$-PL on Amberlite IRC-50 resin with different ion forms}

The adsorption kinetics of $\varepsilon$-PL on the IRC-50 resin with $\mathrm{H}^{+}, \mathrm{Na}^{+}$ and $\mathrm{NH}_{4}{ }^{+}$ion forms are shown in Fig. 3a. The amount of $\varepsilon$-PL that was absorbed by the resin increased with contact time, and adsorption capacities increased linearly during the initial 10 min. Equilibrium of the IRC-50 resin with $\mathrm{H}^{+}, \mathrm{Na}^{+}$and $\mathrm{NH}_{4}{ }^{+}$ reached around 120,150 and $100 \mathrm{~min}$ with $\varepsilon$-PL adsorption capacities of $292.6,430.8$ and $433.0 \mathrm{mg} \mathrm{g}^{-1}$, respectively. Thus, the IRC-50 resin with $\mathrm{H}^{+}, \mathrm{Na}^{+}$and $\mathrm{NH}_{4}{ }^{+}$exhibited a slow adsorption. ${ }^{22}$ The initial linear adsorptive phase most likely
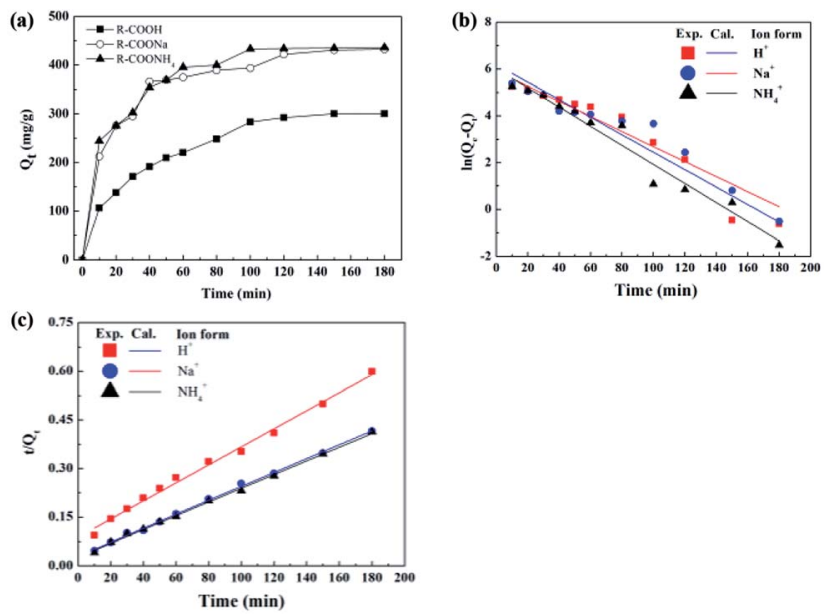

Fig. 3 Static adsorption kinetics of $\varepsilon^{-} \mathrm{PL}$ on Amberlite IRC-50 with $\mathrm{H}^{+}$, $\mathrm{Na}^{+}$and $\mathrm{NH}_{4}{ }^{+}$ion forms at $30{ }^{\circ} \mathrm{C}$. (a) Time profiles of $\varepsilon$ - $\mathrm{PL}$ adsorption on IRC-50 resin with $\mathrm{H}^{+}, \mathrm{Na}^{+}$and $\mathrm{NH}_{4}{ }^{+}$ion forms. (b) Plotting to the pseudo first-order equation. (c) Plotting to the pseudo second-order equation.

results from the availability of more vacant surface sites on the resin to absorb $\varepsilon$-PL. However, with more $\varepsilon$-PL molecules on the resin, the repulsive forces between molecules on the resin surface and the high intra-particle mass transfer resistance in the micropores make $\varepsilon$-PL occupation more difficult, ${ }^{23}$ which slows absorption.

To analyze the adsorption process and to describe the mechanism of $\varepsilon$-PL adsorbed on the resins, the most commonly used pseudo-first-order and pseudo-second-order models were used to plot static adsorption kinetics, with the results shown in Fig. 3b, c and Table 1. In the first-order kinetic model (Fig. 3b), the correlation coefficients $\left(R^{2}\right)$ from the IRC-50 resin with three ion forms were $\sim 0.95$ (Table 1). Such results indicate that the pseudo-first-order equation was unsuitable to describe the mechanism of $\varepsilon$-PL adsorption on the IRC-50 resin. For the pseudo-second-order equation, a plot of $t / Q_{t}$ versus $t$ (Fig. 3c) generated straight lines for all three ion forms with high $R^{2}$ values (0.99) for the model fitting. The calculated $Q_{\mathrm{e}}$ values agreed well with the experimental data (Table 1). These results showed that the adsorption reaction between the $\varepsilon$-PL and the functional groups of the resin follows second-order kinetics, which indicates a mechanism of two-site-occupancy adsorption for an IRC-50 resin with $\mathrm{H}^{+}, \mathrm{Na}^{+}$and $\mathrm{NH}_{4}{ }^{+}$ion forms. Based on the adsorption capacity (Fig. 2a and 3a), $\mathrm{Na}^{+}$and $\mathrm{NH}_{4}{ }^{+}$were selected as a preferable ion form of the IRC-50 resin for $\varepsilon$-PL separation in the following work.

\subsection{Dynamic adsorption of $\varepsilon$-PL on Amberlite IRC-50 with $\mathrm{Na}^{+}$and $\mathrm{NH}_{4}{ }^{+}$ion forms}

Although $\varepsilon$-PL adsorption conditions of IRC-50 resin with $\mathrm{Na}^{+}$ and $\mathrm{NH}_{4}{ }^{+}$were investigated in static experiments, some differences between the static and dynamic experiments may occur. Thus, it is necessary to study the effects of $\mathrm{pH}$ and flow rate on $\varepsilon$ PL adsorption on the IRC-50 resin with $\mathrm{Na}^{+}$and $\mathrm{NH}_{4}{ }^{+}$in the column. 
Table 1 Adsorption kinetics models and parameters for $\varepsilon$-PL on the IRC-50 resin with different ion forms at $30{ }^{\circ} \mathrm{C}$

\begin{tabular}{|c|c|c|c|c|c|c|c|c|}
\hline Ion forms & \multicolumn{4}{|c|}{ Pseudo-first-order model } & \multicolumn{4}{|c|}{ Pseudo-second-order model } \\
\hline $\mathrm{R}-\mathrm{COOH}$ & 0.0860 & 489.5 & 292.6 & 0.9340 & $0.878 \times 10^{-4}$ & 358.4 & 292.6 & 0.9927 \\
\hline $\mathrm{R}-\mathrm{COONa}$ & 0.0742 & 370.2 & 430.8 & 0.9321 & $0.154 \times 10^{-3}$ & 465.3 & 430.8 & 0.9981 \\
\hline $\mathrm{R}-\mathrm{COONH}_{4}$ & 0.0941 & 410.1 & 433.0 & 0.9601 & $0.165 \times 10^{-3}$ & 471.7 & 433.0 & 0.9978 \\
\hline
\end{tabular}

The effect of $\mathrm{pH}$ on $\varepsilon$-PL adsorption on the IRC-50 resin with $\mathrm{Na}^{+}$and $\mathrm{NH}_{4}{ }^{+}$in terms of $\varepsilon$-PL adsorption capacity, and the removal ratios of proteins and pigments are shown in Fig. $4 \mathrm{a}$ and $\mathrm{b}$. The removal ratios of the protein and pigment increased steadily from $\mathrm{pH} 5.5$ to $\mathrm{pH} 8.5$, which suggests that fewer protein impurities and pigments were adsorbed on the IRC-50 resin with $\mathrm{Na}^{+}$accompanying the increase in $\mathrm{pH}$ (Fig. 4a). This result may occur because the pI of most proteins and pigments ranges from $\mathrm{pH} 5.0$ to 7.0, and these impurities would be more negatively charged with an increase in $\mathrm{pH}$. However, the maximum adsorption capacity of the $\varepsilon$-PL on the IRC-50 resin with $\mathrm{Na}^{+}$reached $303.3 \mathrm{mg} \mathrm{g}^{-1}$ at $\mathrm{pH}$ 7.0, which differs from the results obtained in the static experiment (Fig. 2a). When the sample $\mathrm{pH}$ increased further from 7.0 to 8.5, the $\varepsilon$-PL adsorption capacity of the IRC-50 resin with $\mathrm{Na}^{+}$showed a gradual decrease and reached only $74.5 \mathrm{mg} \mathrm{g}^{-1}$ at $\mathrm{pH}$ 8.5. Because the -COONa is a functional group of the IRC-50 resin with $\mathrm{Na}^{+}$, it combines preferentially with $\mathrm{H}^{+}$. The equilibrium $\mathrm{pH}$ of the IRC-50 resin with $\mathrm{Na}^{+}$in a column was $\sim 10.3$. Thus, the column pH would be closer to the pI of $\varepsilon$-PL (9.0) when the sample $\mathrm{pH}$ was increased from 7.0 to 8.5. This behaviour may be responsible for the decrease in $\varepsilon$-PL adsorption capacity of the IRC-50 resin with $\mathrm{Na}^{+}$in the $\mathrm{pH}$ range from 7.0 to 8.5. In particular, the column $\mathrm{pH}$ exceeded 9.0 when the sample $\mathrm{pH}$ was 8.5 , and resulted in an $\varepsilon$-PL charge from positive to negative. The performance of the IRC-50 resin with $\mathrm{NH}_{4}{ }^{+}$for $\varepsilon$-PL
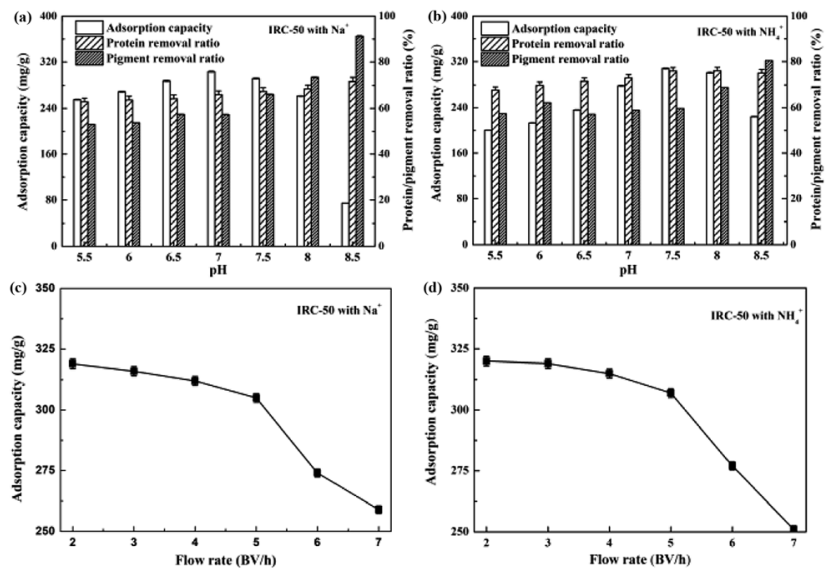

Fig. 4 Effect of $\mathrm{pH}$ and flow rate on dynamic $\varepsilon$ - $\mathrm{PL}$ adsorption on IRC50 resin with $\mathrm{Na}^{+}$and $\mathrm{NH}_{4}^{+}$ion forms. (a) Effect of $\mathrm{pH}$ on $\varepsilon-\mathrm{PL}$ adsorption on IRC-50 resin with $\mathrm{Na}^{+}$, (b) effect of $\mathrm{pH}$ on $\varepsilon-\mathrm{PL}$ adsorption on IRC-50 resin with $\mathrm{NH}_{4}{ }^{+}$, (c) effect of flow rate on $\varepsilon$-PL adsorption on IRC-50 resin with $\mathrm{Na}^{+}$, (d) effect of flow rate on $\varepsilon-\mathrm{PL}$ adsorption on IRC-50 resin with $\mathrm{NH}_{4}{ }^{+}$. extraction exhibited the same tendency as that with $\mathrm{Na}^{+}$, as shown in Fig. 4b. However, the maximum $\varepsilon$-PL adsorption capacity on the IRC-50 resin with $\mathrm{NH}_{4}{ }^{+}$reached $307.9 \mathrm{mg} \mathrm{g}^{-1}$ at $\mathrm{pH} 7.5$, and the minimum $\varepsilon$-PL adsorption capacity was $224.3 \mathrm{mg} \mathrm{g}^{-1}$ at $\mathrm{pH}$ 8.5. Because the equilibrium $\mathrm{pH}$ of the IRC50 resin with $\mathrm{NH}_{4}{ }^{+}$in the column was $\sim 9.8$, the column $\mathrm{pH}$ could not exceed 9.0 when the sample $\mathrm{pH}$ was at/below 8.5, and the $\varepsilon$-PL remained positively charged. Based on the $\varepsilon$-PL adsorption capacity, the optimal sample pHs were 7.0 and 7.5 for the IRC-50 resin with $\mathrm{Na}^{+}$and $\mathrm{NH}_{4}{ }^{+}$, respectively.

The flow rate affected the $\varepsilon$-PL adsorption capacity, and determined the working time. Thus, it is necessary to investigate the effect of flow rate on the $\varepsilon$-PL adsorption capacity. As shown in Fig. 4c and d, the $\varepsilon$-PL adsorption capacities of the IRC-50 resins with $\mathrm{Na}^{+}$and $\mathrm{NH}_{4}{ }^{+}$were reduced only slightly when the flow rate was increased from 2.0 to 5.0 bed volumes (BV) $\mathrm{h}^{-1}$. However, when the flow rate was increased from 5.0 to 7.0 $\mathrm{BV} \mathrm{h}^{-1}$, the $\varepsilon$-PL adsorption capacities of the IRC-50 resins with $\mathrm{Na}^{+}$and $\mathrm{NH}_{4}{ }^{+}$were reduced significantly. As a result, the optimal flow rate of the IRC-50 resins with $\mathrm{Na}^{+}$and $\mathrm{NH}_{4}{ }^{+}$were $5.0 \mathrm{BV} \mathrm{h}^{-1}$, and the corresponding $\varepsilon$-PL adsorption capacities reached 305.1 and $307.2 \mathrm{mg} \mathrm{g}^{-1}$, respectively.

Based on the $\mathrm{pH}$ and flow-rate optimizations, the breakthrough curves of the $\varepsilon$-PL adsorption processes in the columns packed with IRC-50 resin with $\mathrm{Na}^{+}$and $\mathrm{NH}_{4}{ }^{+}$at $5.0 \mathrm{BV} \mathrm{h}{ }^{-1}$ are shown in Fig. 5a and b, respectively. $\varepsilon$-PL was adsorbed completely in the first 51 and $50 \mathrm{BV}$ in both columns. Thereafter, leakage occurred and increased rapidly. As a result, the maximum loading volumes of both resins were 51 and $50 \mathrm{BV}$. The corresponding $\varepsilon$-PL adsorption capacities of both resins reached 303.3 and $308.0 \mathrm{mg} \mathrm{g}^{-1}$.

\subsection{Dynamic desorption of $\varepsilon$-PL on Amberlite IRC-50 with $\mathrm{Na}^{+}$and $\mathrm{NH}_{4}{ }^{+}$ion forms}

Because the desorption ratio is highly dependent on the elution time, the maximum elution time was restricted to $8.0 \mathrm{~h}$ to ensure experiment efficiency. As shown in Table S1, $\dagger$ the $\varepsilon$-PL desorption ratios were less than $90 \%$ when 0.05 and $0.10 \mathrm{~mol} \mathrm{~L}^{-1} \mathrm{NaOH}$ was used as eluent, which indicates that the adsorbed $\varepsilon$-PL on the IRC-50 resin with $\mathrm{Na}^{+}$could not be desorbed completely in $8.0 \mathrm{~h}$ using both eluents. This result was significantly different from those obtained in static experiments (Fig. 2b). When the $\mathrm{NaOH}$ concentration was increased to $0.15 \mathrm{~mol} \mathrm{~L}^{-1}$, the $\varepsilon$-PL desorption ratio was $95.08 \%$ within $7.0 \mathrm{~h}$ of elution. However, with a further increase in $\mathrm{NaOH}$ concentration, the improvement in $\varepsilon$-PL desorption ratio was not 

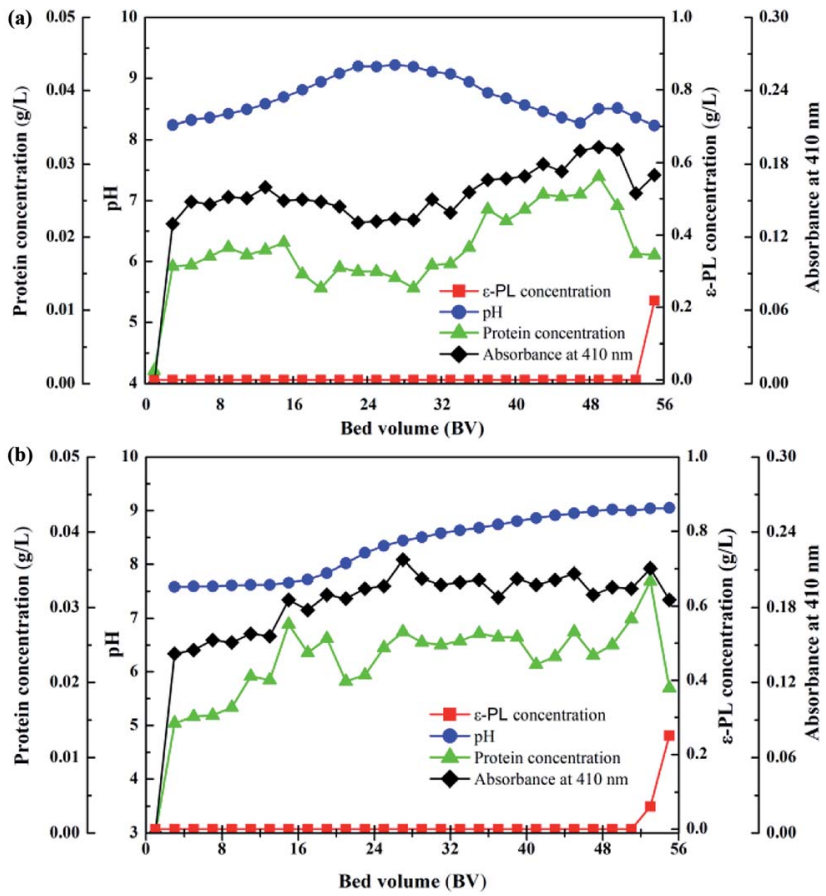

Fig. 5 The breakthrough curves of $\varepsilon$-PL on IRC-50 resins with $\mathrm{Na}^{+}$(a) and $\mathrm{NH}_{4}^{+}$(b) at the flow rate of $5.0 \mathrm{BV} \mathrm{h}^{-1}$.

obvious. Moreover, the consumption of $\mathrm{NaOH}$ was enhanced significantly, which would produce excessive salt in the ensuing operation. Therefore, $0.15 \mathrm{~mol} \mathrm{~L}^{-1} \mathrm{NaOH}$ was used as an eluent for $\varepsilon$-PL desorption on the IRC-50 resin with $\mathrm{Na}^{+}$. Interestingly, as shown in Table $\mathrm{S} 3, \dagger$ the effect of $\mathrm{NH}_{3} \cdot \mathrm{H}_{2} \mathrm{O}$ on the $\varepsilon$-PL desorption on IRC-50 resin with $\mathrm{NH}_{4}{ }^{+}$was similar to that of $\mathrm{NaOH}$. However, the optimal $\mathrm{NH}_{3} \cdot \mathrm{H}_{2} \mathrm{O}$ concentration was $0.20 \mathrm{~mol} \mathrm{~L}^{-1}$.

As shown in Tables S4 and S5, $\uparrow$ the $\varepsilon$-PL desorption ratios exceeded $95 \%$ at various elution rates, regardless of whether IRC-50 resin with $\mathrm{Na}^{+}$using $\mathrm{NaOH}$ as eluent or $\mathrm{NH}_{4}{ }^{+}$using $\mathrm{NH}_{3} \cdot \mathrm{H}_{2} \mathrm{O}$ as eluent was used. No significant difference existed among various elution rates in terms of $\varepsilon$-PL desorption ratio. The elution time decreased with an increase in elution rate, but the decrease in elution time was not obvious when the elution rate exceeded 2.0 $\mathrm{BV} \mathrm{h}{ }^{-1}$. However, the amount of consumed $\mathrm{NaOH}$ or $\mathrm{NH}_{3} \cdot \mathrm{H}_{2} \mathrm{O}$ improved with an increase in elution rate. Therefore, an elution rate of $2.0 \mathrm{BV} \mathrm{h}^{-1}$ was chosen for $\varepsilon$-PL desorption on the IRC-50 resin with $\mathrm{Na}^{+}$and $\mathrm{NH}_{4}{ }^{+}$.

The $\varepsilon$-PL adsorption equilibrium IRC-50 resin with $\mathrm{Na}^{+}$and $\mathrm{NH}_{4}{ }^{+}$was eluted under the optimized desorption conditions based on the above investigation. Deionized water (4 BV) was used for washing both resins before eluting, and the washing and elution processes are shown in Fig. 6. The purpose of washing is to remove impurities that remain on the resin surface, gap and/or bind to the resin with a weak force to improve the purity of the $\varepsilon$-PL during elution. In both IRC-50 resins with $\mathrm{Na}^{+}$and $\mathrm{NH}_{4}{ }^{+}$, the chromaticity decreased gradually, and impurity protein concentration increased initially and then decreased in the washing stage. The $\mathrm{pH}$ increased steadily until washing had finished, which may be derived from the weak acid IRC-50 resin combining with $\mathrm{H}^{+}$from the deionized water. During elution, no $\varepsilon$-PL was eluted in the first $2 \mathrm{BV}$, and the concentrations of protein impurities and pigment increased rapidly. From the third to thirteenth $\mathrm{NaOH}$ or $\mathrm{NH}_{3} \cdot \mathrm{H}_{2} \mathrm{O} \mathrm{BV}, \varepsilon-$ PL was eluted in a normal distribution. Unfortunately, the protein impurities and pigment were eluted with $\varepsilon$-PL, which indicates that additional purification operations are required to improve the $\varepsilon$-PL purity. Finally, as shown in Table S6, $\uparrow$ both IRC-50 resins with $\mathrm{Na}^{+}$and $\mathrm{NH}_{4}{ }^{+}$achieved similar $\varepsilon$-PL purities of $75.86 \%$ and $76.52 \%$, respectively, and of $\sim 45 \%$ higher than that obtained from the IRC-50 resin with $\mathrm{H}^{+}$, which is widely used for $\varepsilon$-PL purification. ${ }^{9,10}$ However, the chromatogram for $\varepsilon$ PL elution from IRC-50 resins with $\mathrm{NH}_{4}{ }^{+}$(Fig. 7e) was better than that for $\mathrm{H}^{+}$(Fig. 7c) and $\mathrm{Na}^{+}$(Fig. 7d) with less impurities, and also superior to the supernatant of fermentation broth (Fig. 7b). Therefore, the IRC-50 resin with $\mathrm{NH}_{4}{ }^{+}$was the best resin for $\varepsilon$-PL extraction from the fermentation broth.

\subsection{Further purification of $\varepsilon$-PL by activated carbon and ultrafiltration}

As shown in Fig. S2, $\dagger \varepsilon$-PL eluted from the IRC-50 resin with $\mathrm{NH}_{4}{ }^{+}$was dark yellow, but the filtrate was nearly colourless after activated carbon decolorization. However, the impurity peak in the decolorization filtrate with a retention time of $6.2 \mathrm{~min}$ could not be removed (Fig. 7f). A large amount of salt was produced during $\mathrm{pH}$ adjustment in the decolorization operation from $\mathrm{pH}$ 11 to $\mathrm{pH}$ 4. Ultrafiltration with a cut-off molecular weight of 1 $\mathrm{kD}$ was used to remove the impurity peak and salt based on our previous study.$^{15}$ The impurity peak was removed completely (Fig. $7 \mathrm{~g}$ ) and residual salt satisfied the standard requirement
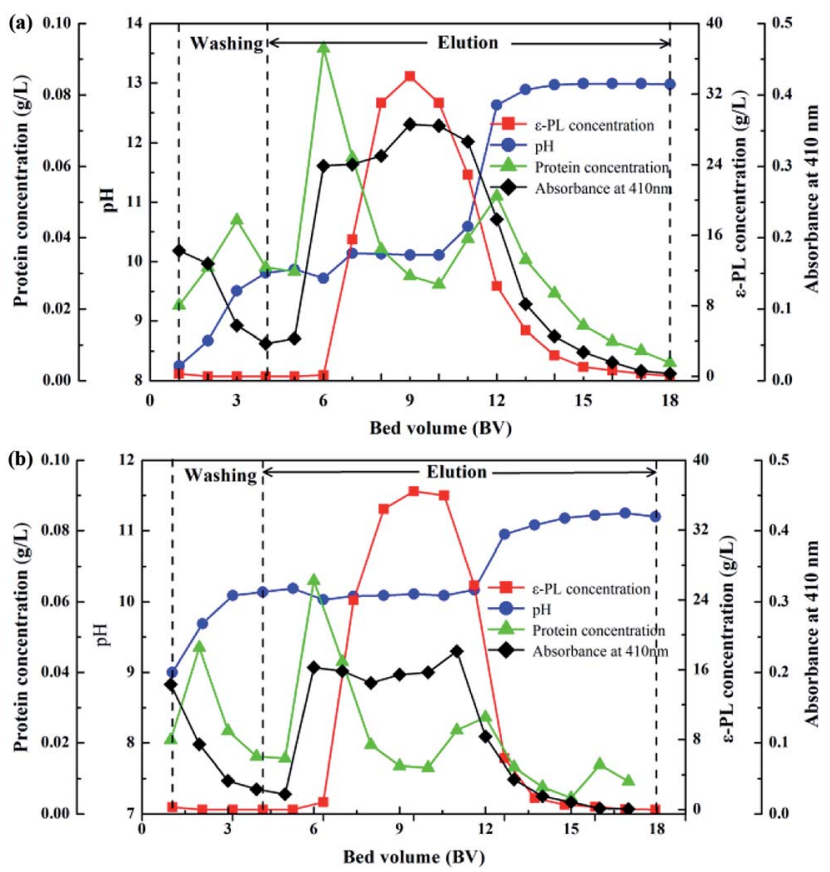

Fig. 6 The elution curves of $\varepsilon$-PL on IRC-50 resin with $\mathrm{Na}^{+}$and $\mathrm{NH}_{4}^{+}$ ion forms. (a). IRC-50 resin with $\mathrm{Na}^{+}$ion form eluted by $0.15 \mathrm{~mol} \mathrm{~L}^{-1}$ $\mathrm{NaOH}$, (b) IRC-50 resin with $\mathrm{NH}_{4}^{+}$eluted by $0.20 \mathrm{~mol} \mathrm{~L}^{-1} \mathrm{NH}_{3} \cdot \mathrm{H}_{2} \mathrm{O}$ at the flow rate of $2.0 \mathrm{BV} \mathrm{h}^{-1}$. 


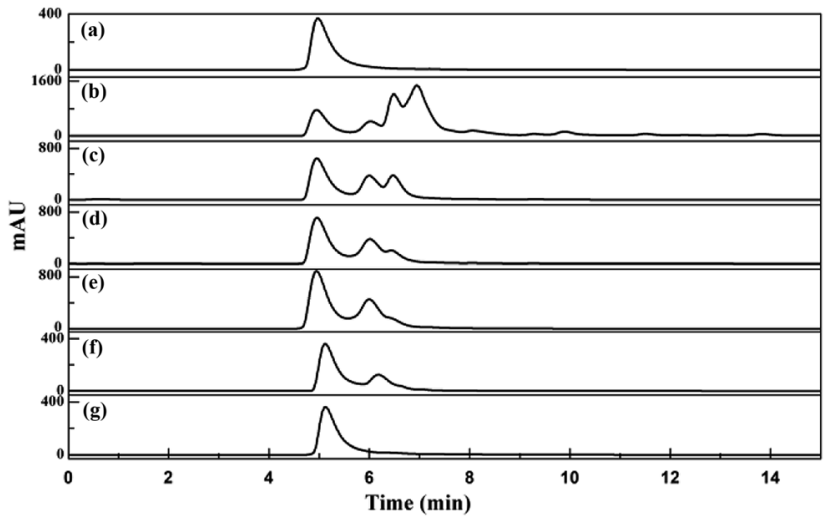

Fig. $7 \mathrm{HPLC}$ chromatograms of each operation in the process of $\varepsilon$-PL extraction at the wavelength of $215 \mathrm{~nm}$. (a) Standard $\varepsilon$-PL sample. (b) Supernatant of fermentation broth. (c) Elution of IRC-50 with $\mathrm{H}^{+}$. (d) Elution of IRC-50 with $\mathrm{Na}^{+}$, (e) elution of IRC-50 with $\mathrm{NH}_{4}{ }^{+}$. (f) Filtrate of decolorization by activated carbon. (g) Retentate of $1 \mathrm{kDa}$ ultrafiltration.

(Table S7 $\dagger$ ). In fact, other physical and chemical parameters of the extracted $\varepsilon$-PL satisfied the standard, including the appearance (Fig. S2 $\dagger$ ) and polymerization degree (Fig. S3†). Based on ten successive operations, as shown in Table $S 8, \uparrow$ the average $\varepsilon$-PL recovery ratio and purity reached $66.01 \% \pm 2.49 \%$ and $97.10 \% \pm 0.95 \%$, respectively, and the average $\varepsilon$-PL adsorption capacity of the IRC-50 resin with $\mathrm{NH}_{4}^{+}$achieved $297.60 \pm 7.63 \mathrm{mg} \mathrm{g}^{-1}$. It is suggested that the reusability of the IRC-50 resin with $\mathrm{NH}_{4}{ }^{+}$was stable in the $\varepsilon$-PL adsorption and impurity-removal capacities.

\section{Conclusions}

Two strong and nine weak acid cation-exchange resins were used for $\varepsilon$-PL extraction, and compared in terms of adsorption capacity and desorption ratio. Amberlite IRC-50 was found to be superior to the other resins. Adsorption kinetics analysis showed that Amberlite IRC-50 resins with $\mathrm{H}^{+}, \mathrm{Na}^{+}$and $\mathrm{NH}_{4}{ }^{+}$ were well fitted to the pseudo-second-order kinetic models. The $\varepsilon$-PL separation parameters of Amberlite IRC-50 resin with $\mathrm{Na}^{+}$ and $\mathrm{NH}_{4}^{+}$were optimized by static and dynamic adsorption/ desorption experiments, and $\mathrm{NH}_{4}{ }^{+}$was the optimal ion form of Amberlite IRC-50 resin used for $\varepsilon$-PL extraction. The $\varepsilon$-PL adsorption capability of Amberlite IRC-50 resin with $\mathrm{NH}_{4}^{+}$ reached $307.96 \mathrm{mg} \mathrm{g}^{-1}$ and the $\varepsilon$-PL purity achieved $76.52 \%$ under optimized operating conditions, i.e., the sample $\mathrm{pH}$ was adjusted to 7.5 and loaded at a flow rate of $5.0 \mathrm{BV} \mathrm{h}^{-1}$, and $0.2 \mathrm{~mol} \mathrm{~L}^{-1} \mathrm{NH}_{3} \cdot \mathrm{H}_{2} \mathrm{O}$ was used as an eluent and eluted at a flow rate of $2.0 \mathrm{BV} \mathrm{h}^{-1}$. The $\varepsilon$-PL purity was improved to $97.10 \% \pm$ $0.95 \%$ with a recovery ratio of $66.01 \% \pm 2.49 \%$ combined with activated carbon and ultrafiltration.

\section{Conflicts of interest}

The authors report no conflicts of interest in this work.

\section{Acknowledgements}

This work was financially supported by the Natural Science Foundation of China (31671846), the Science and Technology Department of Jiangsu Province (BY2016022-25), and the National First-Class Discipline Program of Light Industry Technology and Engineering (LITE2018-27).

\section{References}

1 M. Nishikawa and K. Ogawa, Appl. Environ. Microbiol., 2002, 68, 3575-3581.

2 N. A. El-Sersy, A. E. Abdelwahab, S. S. Abouelkhiir, D. M. Abou-Zeid and S. A. Sabry, J. Basic Microbiol., 2012, 52, 513-522.

3 S. Shima, H. Matsuoka, T. Iwamoto and H. Sakai, J. Antibiot., 1984, 37, 1449-1455.

4 J. Hiraki, Fine Chem., 2000, 29, 18-25.

5 Y. Hamano, Biosci., Biotechnol., Biochem., 2011, 75, 12261233.

6 Z. Xu, Z. Xu, X. Feng, D. Xu, J. Liang and H. Xu, Appl. Microbiol. Biotechnol., 2016, 100, 6619-6630.

7 X. D. Ren, X. S. Chen, X. Zeng, L. Wang, L. Tang and Z. G. Mao, Bioprocess Biosyst. Eng., 2015, 38, 1113-1125.

8 K. K. Cheng, X. B. Zhao, J. Zeng, R. C. Wu, Y. Z. Xu, D. H. Liu and J. A. Zhang, Appl. Microbiol. Biotechnol., 2012, 95, 841850.

9 S. Shima and H. Sakai, Agric. Biol. Chem., 1981, 45, 25032508.

10 S. B. Bankar, S. A. Chaudhary and R. S. Singhal, J. Sci. Ind. Res. India, 2014, 73, 33-40.

11 M. Zhu, Z. Zhang, Y. Liu, F. Wang, L. Xia, J. Xia and H. Guo, Int. J. Polym. Sci., 2016, 3785036.

12 S. Jia, B. Fan, Y. Dai, G. Wang, P. Peng and Y. Jia, Food Sci. Biotechnol., 2010, 19, 361-366.

13 H. Katano, K. Uematsu, C. Maruyama and Y. Hamano, Anal. Sci., 2014, 30, 17-24.

14 S. Li, Z. Ding, J. Liu and X. Cao, Appl. Biochem. Biotechnol., 2017, 183, 1254-1264.

15 X. S. Chen, Y. Gao, B. Zhen, D. Han, J. H. Zhang and Z. G. Mao, Process Biochem., 2016, 51, 134-141.

16 X. S. Chen, K. F. Wang, G. C. Zheng, Y. Gao and Z. G. Mao, Process Biochem., 2018, 68, 22-29.

17 F. R. Itzhaki, Anal. Biochem., 1972, 50, 569-574.

18 M. M. Bradford, Anal. Biochem., 1976, 72, 248-254.

19 M. Nishikawa, Enzyme Microb. Technol., 2009, 45, 295-298.

20 J. Hiraki and T. Ichikawa, Regul. Toxicol. Pharmacol., 2003, 37, 328-340.

21 M. Bishai, S. De, B. Adhikari and R. Banerjee, 3 Biotech., 2015, 5, 455-463.

22 C. Y. Ma, J. Tang, H. X. Wang, G. J. Tao, X. H. Gu and L. M. Hu, J. Sep. Sci., 2009, 32, 185-191.

23 L. S. Lv, J. Tang and C. T. Ho, J. Chem. Technol. Biotechnol., 2008, 83, 1422-1427. 